\title{
Development of Non-Invasive Ultrasonic Measuring System for Monitoring Multiphase Flow in Liquid Media within Composite Pipeline
}

\author{
Mohd Fadzli Abd Shaib ${ }^{1}$, Ruzairi Abd Rahim ${ }^{2}$, S.Z.M. Muji ${ }^{3}$ \\ ${ }^{1,2,3}$ InSet (Instrumentation and Sensing Technology), Department of Mechatronic \& Robotic, \\ Faculty of Electrical \& Electronic Engineering, Universiti Tun Hussein Onn Malaysia, Malaysia \\ ${ }^{2}$ Process Tomography Research Group (PROTOM), Department of Control and Instrumentation Engineering, \\ Faculty of Electrical Engineering, Universiti Teknologi Malaysia, Malaysia
}

\begin{tabular}{l} 
Article Info \\
\hline Article history: \\
Received Jun 8, 2017 \\
Revised Sep 2, 2017 \\
Accepted Sep 16, 2017 \\
\hline
\end{tabular}

Keyword:

Composite pipe

Conveying

Frequency

Non invasive

Ultrasonics

\begin{abstract}
Process of conveying liquid substance via the pipeline is the most common practice of transferring the liquid from one point to another point. Composite pipeline is becoming an option for liquid conveying purposed (instead of PVC, acrylic or metal) for its durability, longer lifetime and non-corrosive material in comparison with current pipeline. In order to ensure, the conveying process has a smooth flow rate without particle or bubble disturbance that could hinder good process flow, non-invasive monitoring system is always required. The ultrasonic measuring system is one of the monitoring options that could be applied. With proper designed for transmitting and conditioning circuitry, $300 \mathrm{kHz}$ ultrasonic frequencies are found as the optimal frequency needed to penetrate across the composite pipeline with full of liquid. The ultrasonic sensor response is being successfully differentiated between full flow (no material blockage) and with bulk material blockage (dry and wet sand).
\end{abstract}

Copyright @ 2017 Institute of Advanced Engineering and Science. All rights reserved.

\section{Corresponding Author:}

Mohd Fadzli Abd Shaib,

InSet (Instrumentation and Sensing Technology),

Department of Mechatronic \& Robotic,

Faculty of Electrical \& Electronic Engineering,

Universiti Tun Hussein Onn Malaysia,

86400, Parit Raja, Johor, Malaysia.

Email: fadzli@uthm.edu.my

\section{INTRODUCTION}

Real time monitoring system for multiphase flow in liquid media plays an important role to observe the internal activities of the system inside the pipeline. This multiphase monitoring system is classified mainly as invasive and non-invasive technique. However, for undisruptive flow inside the pipeline, noninvasive technique is always preferred. Various kinds of internal activities can be observed via this noninvasive monitoring system which depending on the industrial cases. For example, in oil \& gas and water distribution industry, the existing of solid particle in the pipeline such as sand, stone or other unnecessary particle could prevent on producing the expected desired output. Means, at the end of the process flow, the system should be free from this undesirable solid particle to be mixed with crude oil or water. Besides, the existing of these solid particles could cause the erosion of the pipeline elbow, pipe blockage, loss of pipeline wall thickness and damage of the equipment such as filters, pump and valves. Hence, it is great importance to monitor the presence of solid particle to maximize the production rate in these industries.

In cases for water distribution, food and medical (liquid form) industries, the existing of air for liquid flow inside the pipeline could cause major problems in conveying the liquid smoothly inside the 
pipeline. Since air is lighter than water, when the pipe is filled with liquid which initially full of air, air will accumulate at the highest point of the pipeline. As the air continues accumulates at the highest point, the fluid velocity increases force into the smaller opening which finally leads stoppage of the flow. Due to this problem, real time monitoring system is able to observe the existence of air bubble in liquid flow, so that the proper air valve could be designed at specific location to release air trapped in the pipeline.

Non-Invasive ultrasonic measurement system is one of the methods to observe internal activities inside the pipeline. The main advantage of this system is the capability to image two or more component flow in real time manners based on the arrangement of the ultrasonic sensors around the periphery of the system to be observed. In addition, the distribution or flow pattern could be analysed quantitative and qualitative without disrupting the flow of the system (non-invasive and non-intrusively) [1]. The ultrasonic system depends on the sensitivity towards changes of sound energy density (or sound density) where different material or substance owns a different of sound energy density. With this characteristic difference, it will be able to differentiate distribution of different component flow inside the pipeline or the system.

The capability of the ultrasonic sensor depends on the strength of the frequency on each ultrasonic sensor to penetrate the medium. However, the higher the strength of ultrasonic frequency, the projection beam becomes smaller, which not good enough to cover a larger area. Hence, this will affect the measurement accuracy within the coverage area of the pipeline, especially when it involves image construction based data obtained at the receivers. However, this will not become a main problem if it doesn't involve image analysis.

For multiphase flow monitoring system, the capability of the ultrasonic sensor is being explored with different frequency strength and different medium. The type of multiphase flow includes the mixture of liquid and gas, liquid and solid, liquid and liquid or liquid, solid and gas flow within the cross section of the pipeline. The research towards monitoring multiphase flows using ultrasonic measurement system is remaining active up until present days as in Table 1.

Table 1. Meta-analysis for multiphase flow detection via ultrasonic measurement system

\begin{tabular}{|c|c|c|c|}
\hline $\begin{array}{l}\text { Types of } \\
\text { multiphase flow }\end{array}$ & Authors & Year & Application \\
\hline \multirow{4}{*}{ Liquid-solid-gas } & [2] & 2004 & Solid and gas flow in liquid(0.1 to $30 \mathrm{MHz}$ ultrasonic frequencies) \\
\hline & {$[3],[4]$} & 2013 & $\begin{array}{l}\text { Sand-gas-liquid flow in liquid (100kHz to } 750 \mathrm{kHz} \text { ultrasonic frequencies) via steel } \\
\text { pipeline. }\end{array}$ \\
\hline & [5] & 2010 & PVC-water flow -different size of PVC size been explored $(40 \mathrm{kHz})$ \\
\hline & [6] & 2011 & Oil-Sand flow (5-10MHz ultrasonic frequency) via pulse echo techniques \\
\hline \multirow[t]{4}{*}{ Liquid-solid } & [7] & 2012 & PVC/Ceramic/Steel-water flow (20kHz ultrasonic frequency) \\
\hline & [8] & 2012 & Water-glass bead (2-12MHz ultrasonic frequency) in high shear flow \\
\hline & [9] & 2015 & Water/heavy -Sand flow (100-500kHz ultrasonic frequency) \\
\hline & [10] & 2007 & Oil-water flow (40kHz ultrasonic frequency) \\
\hline \multirow[t]{2}{*}{ Liquid-liquid } & [11] & 2009 & Corn oil/Soy bean oil/Palm oil-water flow $(40 \mathrm{kHz}$ ultrasonic frequency) \\
\hline & [12] & 2009 & Water-Oil flow-time of flight technique \\
\hline \multirow[t]{7}{*}{ Liquid-gas } & [13] & 2007 & $\begin{array}{l}\text { Liquid-gas flow ( } 2 \mathrm{MHz} \text { ultrasonic frequency)- methyl- methacrylate material for } \\
\text { rectangular container. }\end{array}$ \\
\hline & [14] & 2010 & $\begin{array}{l}\text { Liquid-gas flow( } 4 \mathrm{Mhz} \text { ultrasonic frequency) using three type ultrasound interface } \\
\text { detection techniques }\end{array}$ \\
\hline & {$[15]$} & 2010 & $\begin{array}{l}\text { Liquid-gas flow ( } 40 \mathrm{kHz} \text { ultrasonic frequency)-simulation on optimum number of } \\
\text { ultrasonic sensor. }\end{array}$ \\
\hline & {$[16],[17]$} & $\begin{array}{l}2013, \\
2014\end{array}$ & Liquid-Gas flow (40kHz and $333 \mathrm{kHz}$ ultrasonic frequency) \\
\hline & [18] & 2014 & Liquid-gas flow $(150-750 \mathrm{kHz})$, measure slug velocity \\
\hline & [19]-[22] & $\begin{array}{l}2008- \\
2014\end{array}$ & Liquid-gas flow(333kHz ultrasonic frequency)-32 transceivers \\
\hline & {$[23]-[25]$} & $\begin{array}{l}2010- \\
2013\end{array}$ & Liquid-gas flow( $333 \mathrm{kHz}$ ultrasonic frequency)-16 pairs \\
\hline
\end{tabular}

\section{SYSTEM OVERVIEW}

In developing the ultrasonic measurement system, it will be divided into two major parts which are hardware and software part as in Figure 1. The main process of constructing the hardware is selecting the right frequency of ultrasonic transducers. The frequency selection of ultrasonic transducers is one of the main factors to observe the penetration capability inside the pipeline. However, there are also other factors involved in signal penetration which are the types of pipe used and the type of distribution of material in the liquid flow. The arrangement of ultrasonic transducers around the periphery of the pipeline is vital to achieve the best results. The minimum pairs of ultrasonic transducer is only one pair if does not involve image 
construction (only signal analysis) and the maximum pairs is depends on the circumference size of the pipeline. The object could be single or more than one component or substance. The signal will be excited from the ultrasonic transducer as a transmitter and other ultrasonic transducer will act as a receiver. The transmitting and receiving signal is controlled via microcontroller for further analysis.

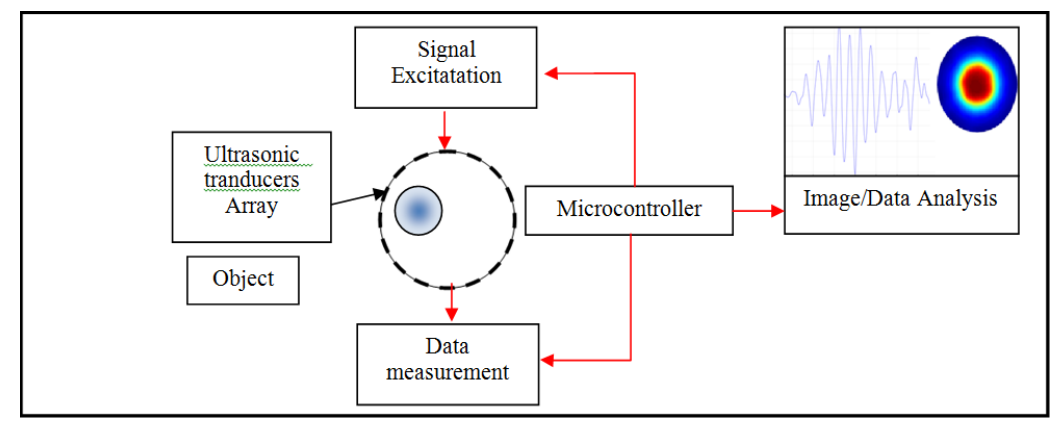

Figure 1. The whole concept of Ultrasonic measurement system

Generally, most pipelines for conveying the substance (in liquid form) made from acrylic, PVC and metal. However, due to the limitation and weaknesses of the characteristics of the currents pipe possessed, most of the industry starts to explore other potential pipe that can offer better strength to meet industrial expectation. There are several other alternative pipes available in the market and one of it is the composite pipe. Due to the good feature of the composite pipe, which has longer lifetime, non-corrosive and strong enough to withstand with high pressure, this pipe has been chosen as an alternative pipe for process of conveying material.

Polyethylene (Poly) Aluminum (Al) composite pipe is used in this research. This composite pipe mainly consists of three layers of material, which are the internal layer (Polyethylene), middle layer (Aluminum) and outer layer (Polyethylene). Between each layer of the composite pipe, there is a thin adhesive layer to ensure the polyethylene and aluminum layer are intact. The thickness of each polyethylene and aluminum layer is different. The thickness of Polyethylene Aluminium composite pipe is shown in Figure 2. The outer layer and internal of Polyethylene is $3 \mathrm{~mm}$ and $3.5 \mathrm{~mm}$ thickness consecutively. The aluminium layer at the middle layer is $1 \mathrm{~mm}$ which strengthens the structure of the composite pipe. Generally, this composite pipe is $7.5 \mathrm{~mm}$ thickness where internal diameter is $60 \mathrm{~mm}$ and outer diameter is $75 \mathrm{~mm}$.

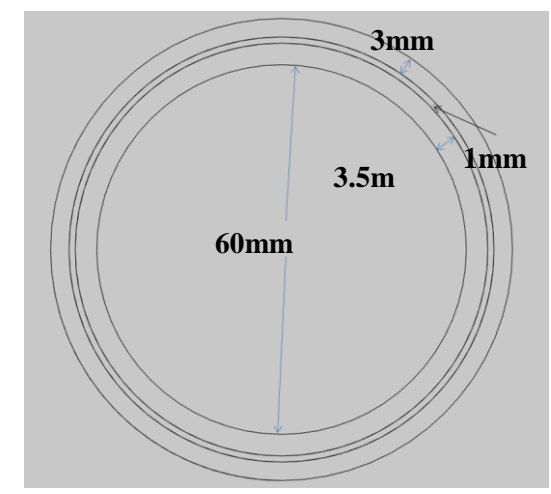

Figure 2. Polyethylene Aluminium composite multiple layer thickness

For ultrasonic wave propagates from one medium to another medium, it need to travel through several boundaries before reaching at the receiver. The ultrasonic signal is either transmitted or reflected depends on the acoustic impedance of each material. If the acoustic impedance between one materials very high compared with other material, more signals will be reflected. When the acoustic impedance of two materials is almost the same, the signal will be more transmitted. The total amount of ultrasonic signal reflected and transmitted must be equal to the total amount of incident energy. 
In case of the penetration capability of ultrasonic sensor through Polyethylene Aluminium composite pipe, there are several layers of boundaries need to be considered where pairs of ultrasonic sensors are being located at the periphery of the pipeline as in Figure 3. The amount of reflected or transmitted signal is determined from the Equation (1) and Equation (2) based on the different acoustic impedance on every boundary layer.
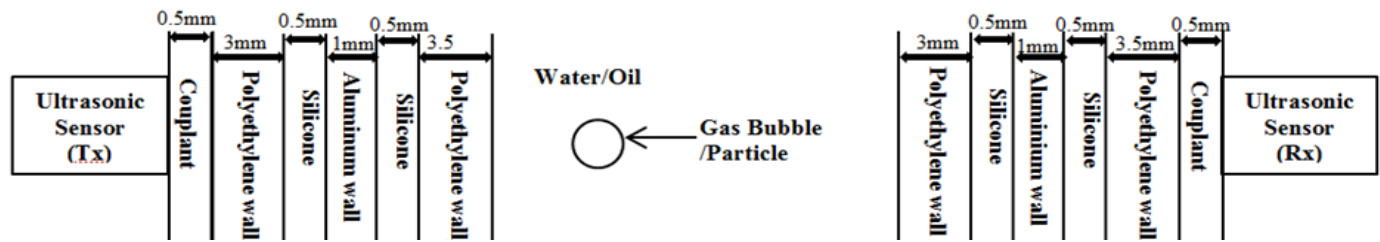

Figure 3. Cut of Section of Polyethylene Aluminium composite pipe

$$
\begin{aligned}
& R=\left[\frac{\left(Z_{2}-Z_{1}\right)}{\left(Z_{2}+Z_{1}\right)}\right]^{2} \\
& T=\frac{\left(4 Z_{1} Z_{2}\right)}{\left(Z_{2}+Z_{1}\right)^{2}}=1-\mathrm{R}
\end{aligned}
$$

Where

$\mathrm{R}$ is reflected coefficient

$\mathrm{T}$ is transmitted coefficient

$\mathrm{Z}_{1}$ is acoustic impedance of material 1

$\mathrm{Z}_{2}$ is acoustic impedance of material 2

For each boundary layer, when the ultrasonic signal travelling a distance and block by an obstacle, the signals will be transmitted or reflected which is depends on the acoustic impedance of the material or obstacle as visualised in Figure 4. Means, only part of the signal will be received by ultrasonic receiver and the rest of the signal will be reflected.

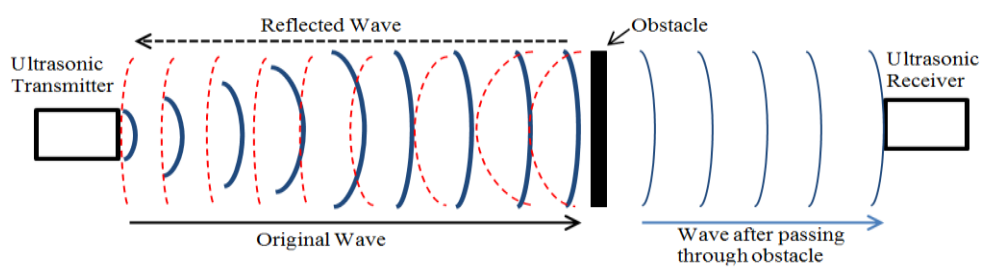

Figure 4. Ultrasonic signal pattern when blocked with an obstacle

\section{CONSTRUCTION OF ULTRASONIC MEASUREMENT SYSTEM}

The ultrasonic sensor contains a piezoelectric crystal that will vibrate in the form of the frequency wave with the triggered by pulse voltage. The lower the frequency of ultrasonic sensors will have higher wavelength and penetration capability into the material. However, the higher the frequency will lead to lower wavelength, hence, lower penetration capability of the material with higher resolution compared with the lower frequency ultrasonic sensor. This is the reason, the ultrasonic sensor with lower frequency is being chosen to construct this ultrasonic measurement system due to its capability for deeper penetration.

\subsection{The Measuring Process for Ultrasonic Measuring System}

Ultrasonic transceivers model MCUSD13A300B09RS with a frequency of $300 \mathrm{kHz}$ with central frequency of $300 \mathrm{kHz} \pm 15 \mathrm{kHz}$ is being chosen in this project. This type of ultrasonic sensors can transmit or receive the signal at the same time. For developing the ultrasonic measurement system, involves the integration of hardware and software part. The hardware part includes the setup of the hardware arrangement as in Figure 5. Pairs of ultrasonic sensor are attached at the circumference of the composite pipeline full with

Development of Non-Invasive Ultrasonic Measuring System for Monitoring .... (Mohd Fadzli Abd Shaib) 
liquid (water) using glycerine. Each ultrasonic sensor connected with its unique circuity for the purposed of transmitting and receiving ultrasonic signal.

The circuitry of the ultrasonic system includes the integration between PC and microcontrollers, excitation and signal conditioning circuit with the set of ultrasonic sensors as shown in Figure 6. For this system to operate, simple $\mathrm{C}$ programming languages are developed via MicroC compiler to generate pulses to dsPIC30F6010A microcontroller. The generated pulse will be sent to analogue switches. The sensor will act as a transmitter or as a receiver depends on the signal obtained from the analogue switches. For pairs of ultrasonic transceivers, in order to determine the sensor as a transmitter or a receiver, different configuration of analogue switches needs to be set. From Figure 7, two analogue switches model MAX319 are needed to set the first sensor (S1) as the transmitter and second sensor (S2) as receiver. The first analogue switch is injected with a positive pulse at port 6 . This will cause port 1 and port 8 is short circuited. Hence, sensor 1 (located at port 1) and transmitter circuit (located at port 8) is connected which make S1 as transmitter. Ultrasonic signal transmission across the composite pipe is occurring. On a contrary, there is no pulse is injected at port 6. Sensor S2 (located at port 1) and receiver circuit (located at port 2) is connected makes sensor S2 as a receiver. The received signal is being processed through the receiver (signal conditioning) circuit and the data will be collected to a PC through the microcontroller.

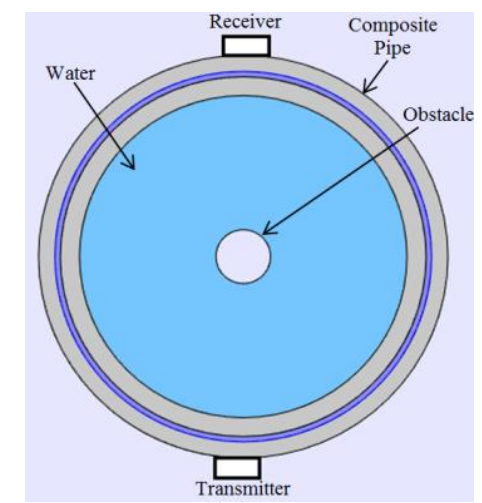

Figure 5. Arrangement of ultrasonic sensor on the periphery of the composite pipeline

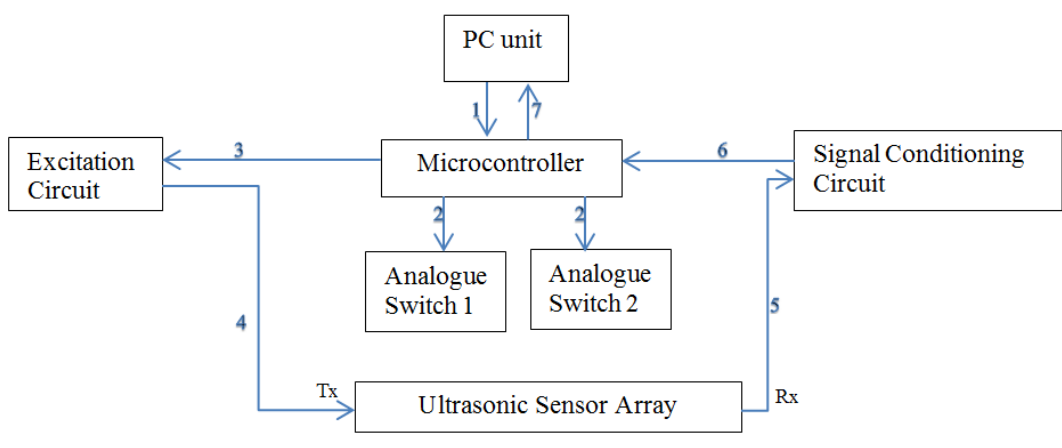

Figure 6. Process of obtain data from ultrasonic sensor
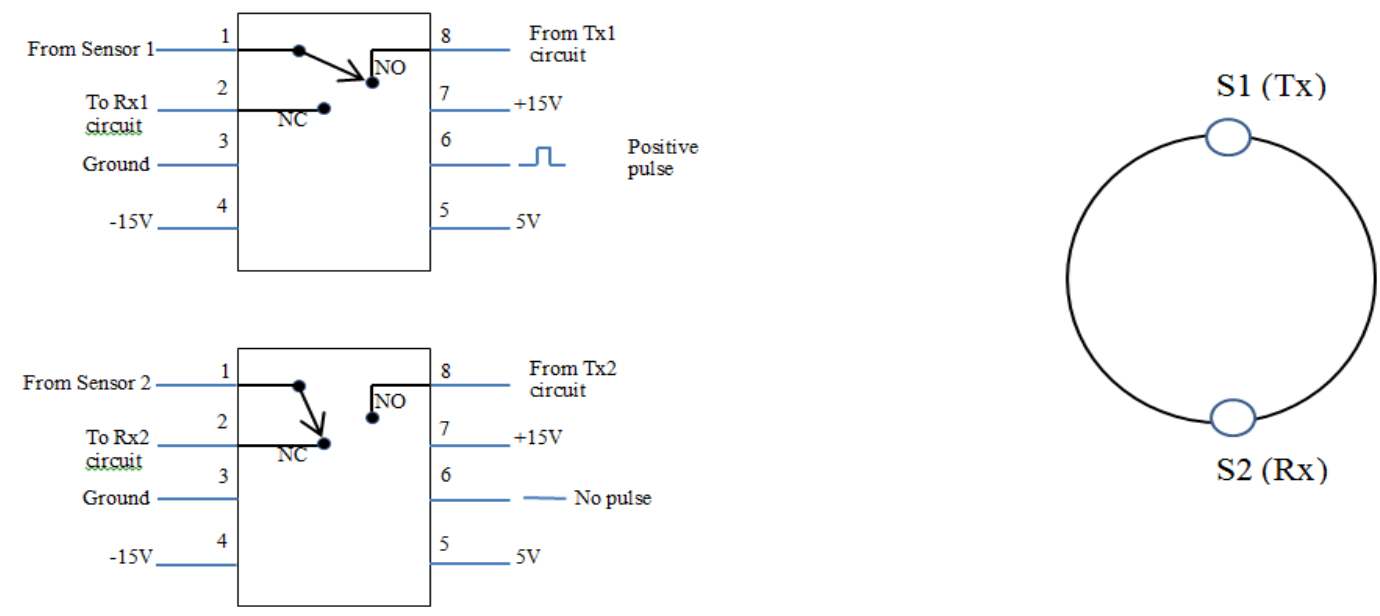

Figure 7. Configuration of analogue switches for $\mathrm{S} 1$ as transmitter and $\mathrm{S} 2$ as receiver

As for another configuration, $\mathrm{S} 2$ as transmitter and $\mathrm{S} 1$ as receiver, the arrangement is reverse compared from Figure 7 which is shown in Figure 8. 

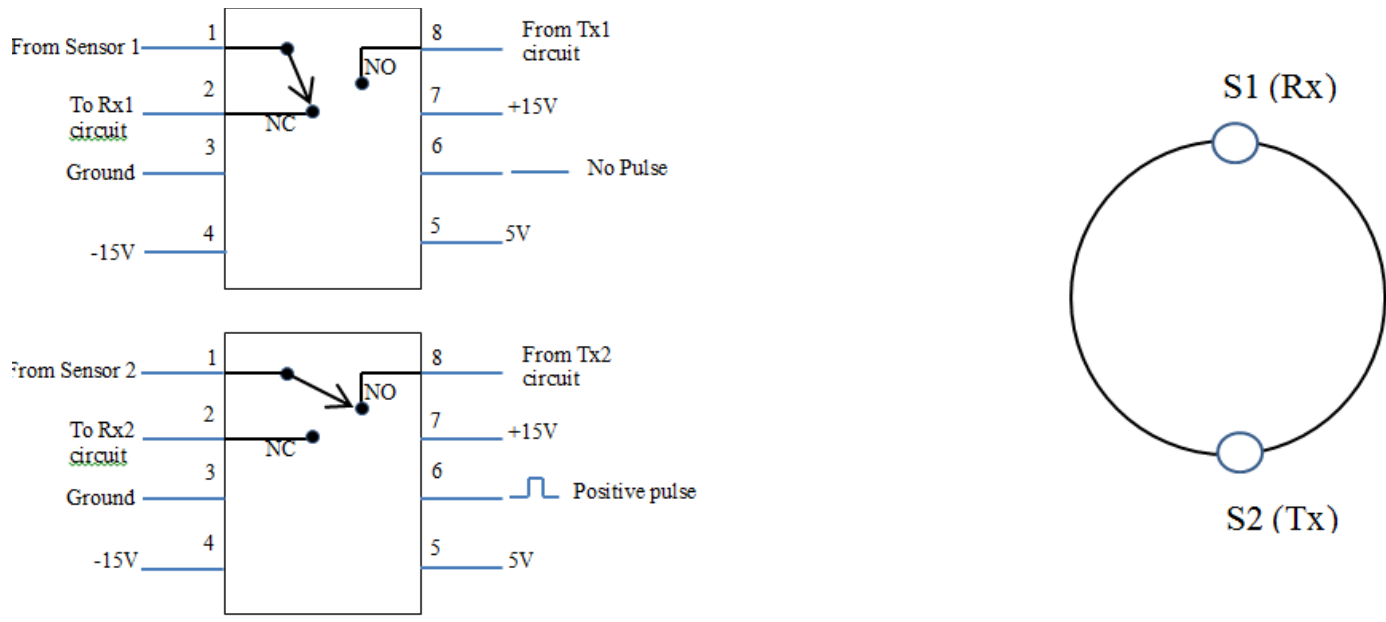

Figure 8. Configuration of analogue switches for $\mathrm{S} 1$ as receiver and $\mathrm{S} 2$ as transmitter

\section{DESIGNING TRANSMITTER AND SIGNAL CONDITIONING CIRCUIT}

In order to operate the ultrasonics transceiver, two type of circuitry need to be designed which is transmitter and signal conditioning circuit.

\subsection{Transmitter Circuit}

In activating ultrasonic sensor as transmitting purpose, dual pulse with $30 \mathrm{~V}$ in amplitude and $300 \mathrm{kHz}$ frequency need to be triggered at the sensor every $100 \mathrm{~Hz}$ of period. This is important so that reverberation effect totally finish before new excitation start. Hence, to meet the requirement, comparator circuit need to be constructed as in Figure 9.

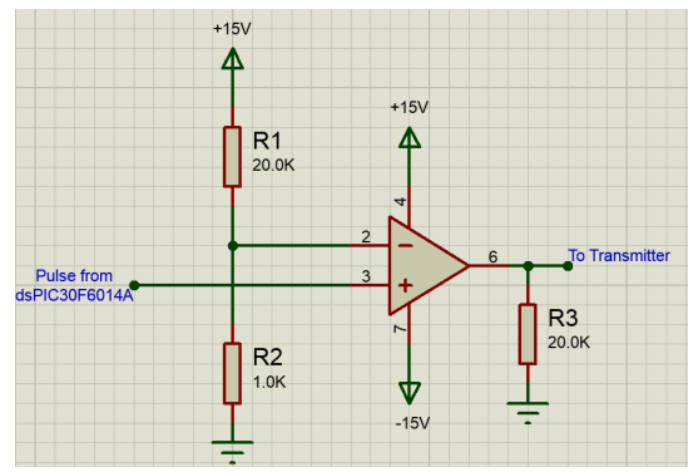

Figure 9. Transmitter circuit

In design of comparator circuit, below formula is followed:

If $\mathrm{V}^{+}>\mathrm{V}_{\text {ref }}$, then $\mathrm{V}_{\text {out }}=+\mathrm{V}_{\mathrm{cc}}$

If $\mathrm{V}^{+}<\mathrm{V}_{\text {ref }}$, then $\mathrm{V}_{\text {out }}=-\mathrm{V}_{\mathrm{cc}}$

Where

$$
\begin{aligned}
\mathrm{V}_{\text {ref }} & =(\mathrm{R} 2 / \mathrm{R} 1+\mathrm{R} 2) \times \mathrm{V}_{\mathrm{cc}} \\
& =(1 \mathrm{k} / 1 \mathrm{k}+20 \mathrm{k}) \times 15 \\
& =0.7 \mathrm{~V}
\end{aligned}
$$

Since non-inverting input voltage obtains pulse swing from $0 \mathrm{~V}$ to $5 \mathrm{~V}$, the comparator will generate approximately $30 \mathrm{~V}$ peak to peak voltage at $300 \mathrm{kHz}$ as shown in Figure 10 . This $30 \mathrm{~V}$ peak to peak voltage will be injected to ultrasonic transducers which will act as the transmitter.

Development of Non-Invasive Ultrasonic Measuring System for Monitoring .... (Mohd Fadzli Abd Shaib) 


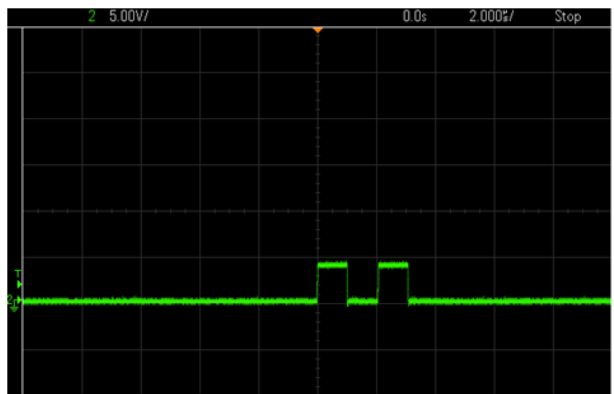

(a)

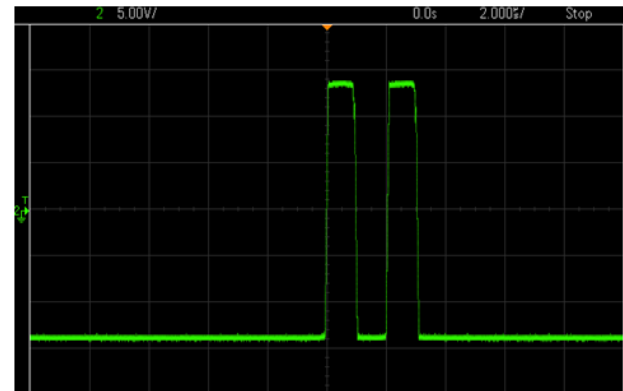

(b)

Figure 10. Dual Pulse Generated via dsPIC30F6014A (a) Original signal from dsPIC30F6014A, (b) Signal been amplified by comparator circuit

\subsection{Signal Conditioning Circuit}

When the ultrasonic sensor transmits the signal through the composite pipe, it needs to travels through several obstacles which are composite pipe, liquid, bubble and other impurities in the liquid in order to reach the receiver. This will cause very small signal that will be arriving and detected at the receiver. Most of the signal will be reflected by the obstacle. Since the detected signal is extremely small which is several microvolts, this signal need to be amplified. Hence, the most suitable amplifier is being designed to meet the requirement. In order to design inverting amplifier, high speed amplifier model LT1226 is selected based on its high gain bandwidth product which is $1 \mathrm{GHz}$. This inverting amplifier has gain of -100 . The gain chosen must be within the acceptable range, or else the signal will be clipped when it reach the saturation level. From Figure 11, Channel 1(Yellow colour signal) represents first amplified signal from the amplifier circuit as in Figure 11(b) and Channel 2(Green colour signal) represents transmitting signal. From Figure 11(b) which the zoom image of the amplified signal, the travelling time from the transmitter to reach the receiver (based from the first highest signal magnitude) is 54us. The signal at the receiver before the signal is transmitted is ignored since it is considered as a noise. The first highest peak signal contains high noise, hence, need to be filtered before being amplified for the second time. The first highest magnitude of the receivers is only $612.5 \mathrm{mV}$ where the composite pipe is contained with plain water. This magnitude is still considered very small which need to be further amplified.

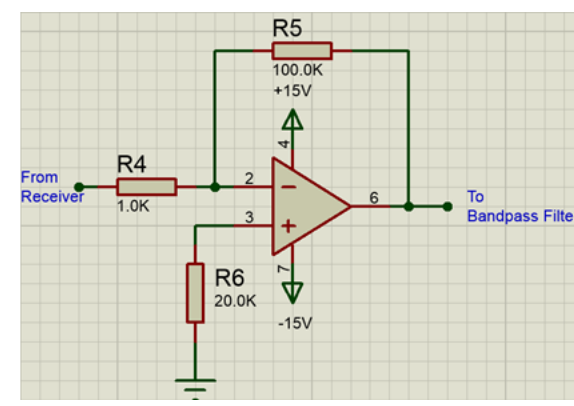

(a)

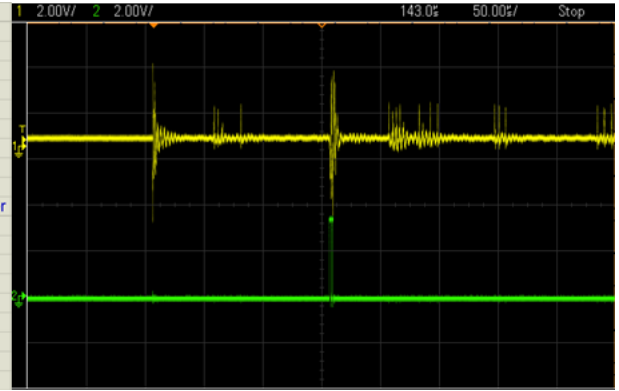

(b)

Figure 11. First amplification stage (a) Inverting amplifier, (b) Amplified ultrasonic signal

Since the first amplification stage from Figure 11 contained high noise and very small signal, it need to be filtered via bandpass filter. The type of filter to reduce the noise is a Multiple Feedback Bandpass Filter where the centre frequency is chosen as $300 \mathrm{kHz}$ which is the same as the frequency of the ultrasonic transducers as in Figure 12. The magnitude of the signal after being filtered is $156.25 \mathrm{mV}$. This means the signal is further reduced when passing this Multiple Feedback Bandpass Filter. However, the filtered signal as in Figure 12(b) is free from signal other than $300 \mathrm{kHz}$ which is considered as noise. 
In order to design Multiple Feedback Bandpass Filter as in Figure 12(a), there are several aspects need to be considered which are Centre Frequency, Bandwidth and Quality Factor. In this case, since the frequency of the ultrasonic transducers is $300 \mathrm{kHz}$, centre of frequency should be $300 \mathrm{kHz}$ where upper frequency is $315 \mathrm{kHz}$ and lower frequency is $285 \mathrm{kHz}$. In the calculation of value of resistors and capacitors needed, Equation (1) till Equation (5) is considered [26]. However, the capacitance value of C1 and C2 are considered the same which is $100 \mathrm{pF}$.

$$
\begin{aligned}
B W & =F_{H}-F_{L} \\
& =315 \mathrm{kHz}-285 \mathrm{k} \\
& =30 \mathrm{kHz} \\
Q= & f_{o} / B W \\
= & \frac{300000 \mathrm{kHz}}{3000 \mathrm{kHz}} \\
= & 10
\end{aligned}
$$

where

$B W=$ Frequency bandwidth

$f_{o}=$ Centre frequency

$F_{H}=$ Upper frequency

$F_{L}=$ Lower frequency

$\mathrm{Q}=$ Quality Factor

So, based on the Equation (1) till (5), the value of the nearest available resistor is chosen for design Multiple Bandpass Filter circuit.

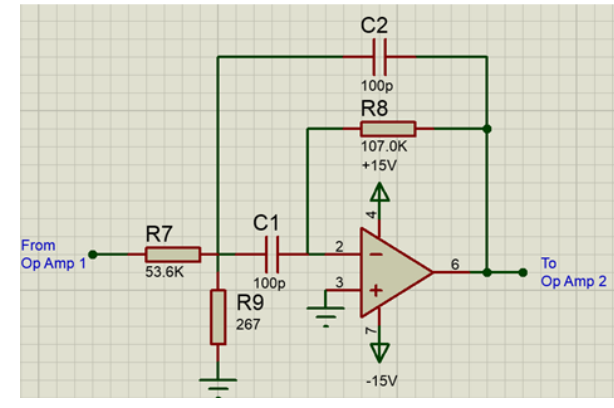

(a)

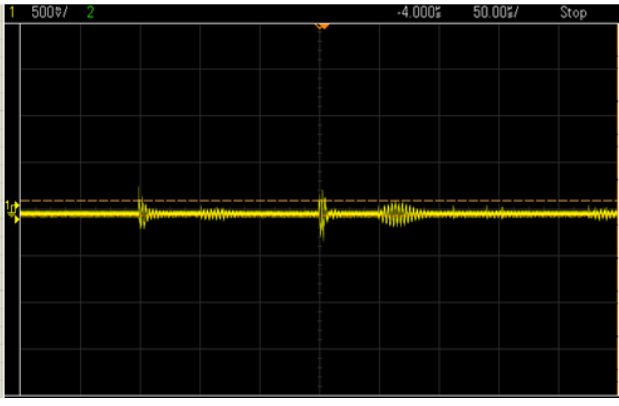

(b)

Figure 12. Filtering stage (a) Multiple Feedback Bandpass Filter circuit, (b) Filtered signal (after passing Multiple Feedback Bandpass Filter)

The small magnitude of the signal obtained after passing the Multiple Feedback Bandpass Filter need to be amplified further by the second amplifier. This is vital so that the signal obtained will be significant to be transferred to the PC to be analysed. After being amplified for gain of -53.6, the first highest

Development of Non-Invasive Ultrasonic Measuring System for Monitoring .... (Mohd Fadzli Abd Shaib) 
magnitude is increase from $156.25 \mathrm{mV}$ to $6.75 \mathrm{~V}$ which considered significant enough for further analysis as in Figure 13(b). The amplified signal consists of information signal and carrier signal (300kHz) which is called modulated signal. This modulated signal will pass through a peak detector circuit that will eliminate the carrier signal which detects the unmodulated signal. This unmodulated signal is only consists of information signal after passing through the envelope detector circuitry.

From Peak Detector circuit based on Figure 14(a), the diode, D1 is to eliminate the negative side of the amplified signal from Figure 14(b) and the combination of C4 parallel with R13 is to eliminate carrier signal.

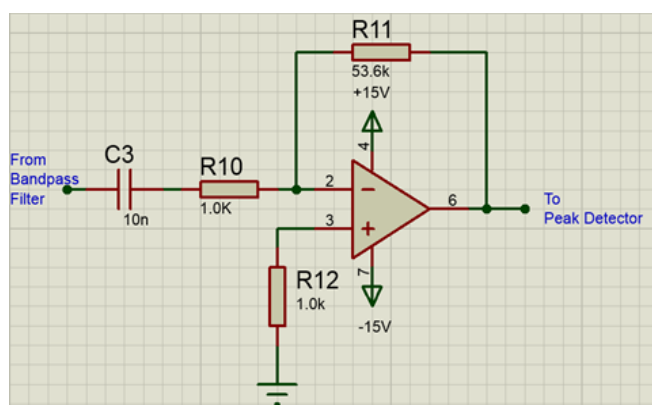

(a)

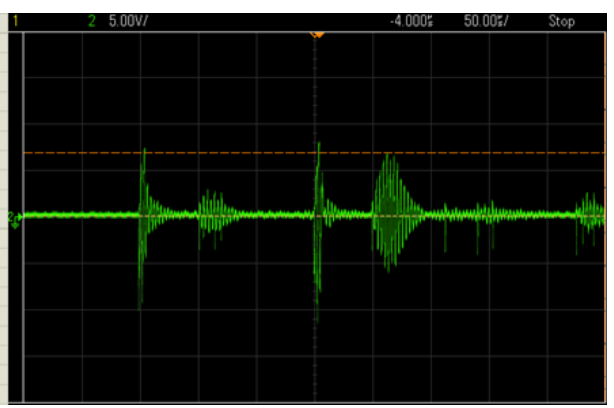

(b)

Figure 13. Second amplification stage (a) Inverting Amplifier circuit, (b) Amplified signal

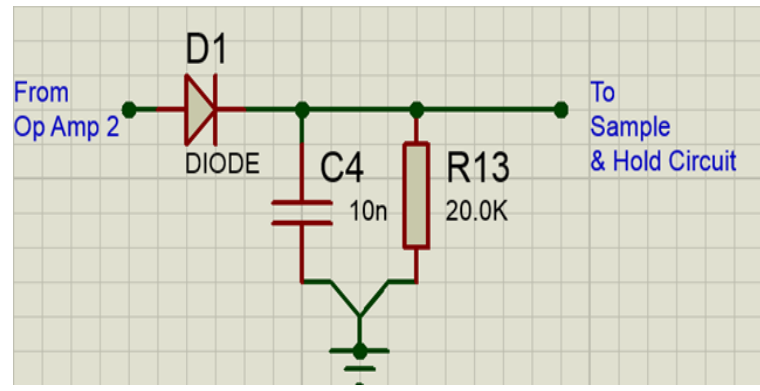

(a)

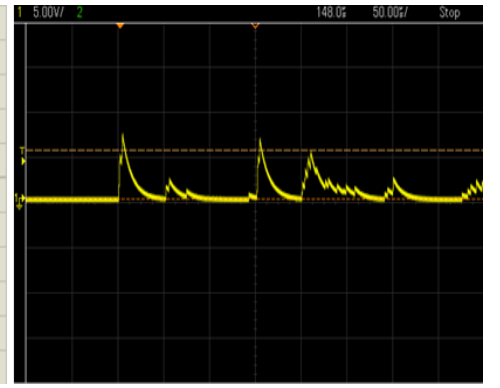

(b)

Figure 14. Information detecting stage (a) Peak Detector circuit, (b) Information signal

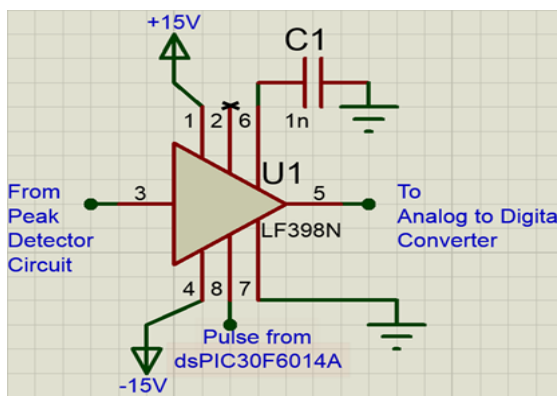

(a)

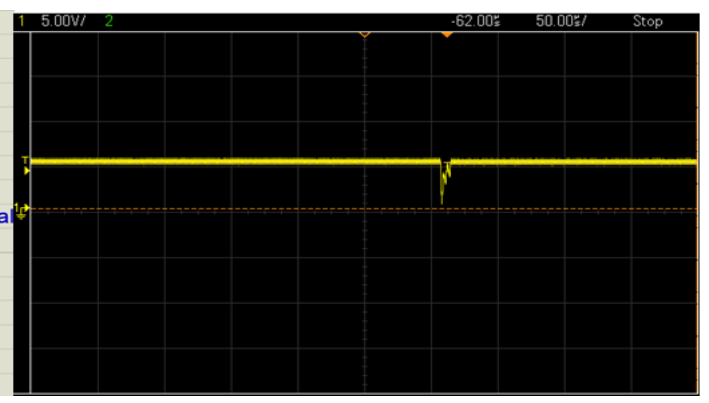

(b)

Figure 15. Sampling stage (a) Sample \& Hold circuit, (b) Sampling signal

In order for the information signal to be sent to PC for further analysis, the desired signal should be identified before being transferred. Based from Figure 15(a), in order the sample and hold the accurate signal, 
another pulse need to be injected to pin 8 of monolithic sample and hold circuit. Hence, the highest peak of the magnitude of the chosen signal will be sampled and hold the same state before being fed to microcontroller dsPIC30F6010A. As a result, the sampling signal is obtained as in Figure 15(b). The output signals of the sample and hold circuit is $5 \mathrm{~V}$ which is then transferred to a PC through Analog to Digital Converter port. This value is obtained when there is no bubble or material blockage between the paths between two ultrasonic transceivers that is mounted on the wall of the composite pipe. Whenever, there is a blockage between it, the magnitude of the ultrasonic transceiver will be reduced.

\section{DESIGNING TRANSMITTER AND SIGNAL CONDITIONING CIRCUIT}

Based on the previous section, the signal of the ultrasonic transceiver is being observed when the composite pipe full with water without any impurities such as bubble, sand or other particle. In this section, the impurities are introduced and being placed at the middle diameter of the pipeline and the magnitude is observed. For simplicity, inside the composite pipe which is full with water, in the middle of the diameter of the composite pipe, the cylinder made from hollow thin acrylic is being placed. For simplicity, the hollow of acrylic cylinder pipe is placed at the middle of the centre of the acrylic pipe. This hollow pipe is filled with sand as in Figure 16. It is assumed full sand flow occurred in the middle of the pipeline. Difference size in term of diameter of sand flow in bulk is considered.

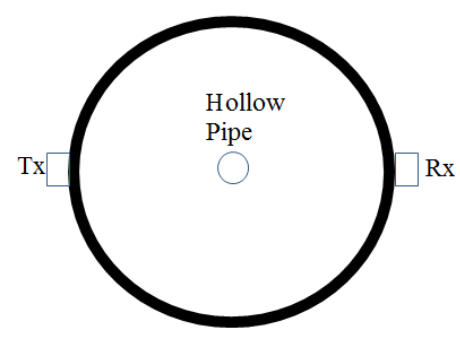

Figure 16. Location of the obstacle inside the composite pipeline

Several diameters of hollow pipe with different diameter fill with full of sand has been tested. There are two types of sand has been tested, which are dry and wet sand. From the voltage distribution between two types of sand as in Figure 17, as the diameter of the sand in bulk is increased, the magnitude of the voltage is decreased for both types of sand. However, in comparison of voltage between dry and wet sand, wet send contributes higher voltage reading in comparison with dry sand. This is due to a lot of air void between the sand particles for the dry sands, which hinder the ultrasonic signal in reaching the receiver of the ultrasonic transducer. However, for wet sand, the air void has reduced, hence the higher amount of ultrasonic signal could reach the receiver. The voltage reading is dropped to zero when the diameter of bulk of sand more than $22 \mathrm{~mm}$ indicates the ultrasonic signal is fully blocked by the impurities.

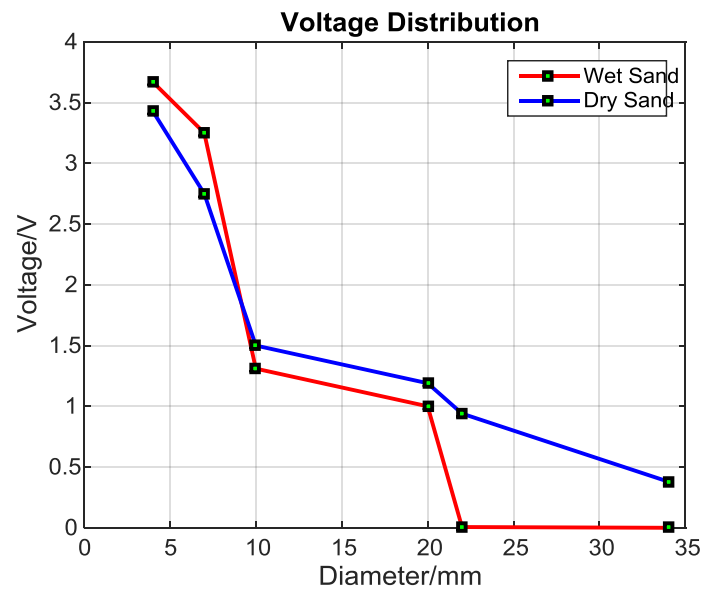

Figure 17. Voltage distribution of Ultrasonic signal for different group of sand in bulk 


\section{CONCLUSION}

From the circuitry design for transmitting and receiving the ultrasonic signals, it is proved that this signal from $300 \mathrm{kHz}$ ultrasonic transducers are capable to penetrate the wall of the Polyethylene Aluminium composite pipeline. However, the received signal is too small when reach at the receiver even though has been amplified with a certain amount of gain. This weak ultrasonic needs multiple amplification and filtering technique to obtain an acceptable range of voltage that can be processed further for analogue to digital conversion by the microcontroller before being fed to the PC. The received signal showed a significance difference when the composite pipe is only full with water and when the signal is obstructed with bulk of sand. In addition, whenever the bulk of sand changes its size, the voltage reading of the signal also decreases whenever the size of bulk of sand increase. This indicates, this system could differentiate different kinds of the size of the particle that exists in bulk forms.

\section{ACKNOWLEDGEMENTS}

The author would like to thank to Universiti Teknologi Malaysia and Universiti Tun Hussein Onn Malaysia for supporting the facilities and funding for this research.

\section{REFERENCES}

[1] R. A. Rahim, M. H. F. Rahiman, K. S. Chan, and S. W. Nawawi, "Non-invasive imaging of liquid/gas flow using ultrasonic transmission-mode tomography," Sensors Actuators, A Phys., vol. 135, no. 2, pp. 337-345, 2007.

[2] Y. Zheng and Q. Zhang, "Simultaneous measurement of gas and solid holdups in multiphase systems using ultrasonic technique," Chem. Eng. Sci., vol. 59, no. 17, pp. 3505-3514, 2004.

[3] M. El-Alej, D. Mba, T. Yan, and M. Elforgani, "Monitoring Sand Transport Characteristics in Multiphase Flow in Horizontal Pipelines Using Acoustic Emission Technology,” vol. 7, no. 6, pp. 892-898, 2013.

[4] M. E. El-Alej, "Monitoring Sand Particle Concentration in Multiphase Flow Using Acoustic Emission Technology," pp. 2013-2014, 2014.

[5] M. H. Fazalul Rahiman and R. Abdul Rahim, "Development of Ultrasonic Transmission-Mode Tomography for Water-Particles Flow," Sensors \& Transducer, vol. 117, no. 6, pp. 99-105, 2010.

[6] A. Silva, "Ultrasound mesurement of the content of solid particles in liquid media applied to oil industry," in 21st International of Congress of Mechanical Engineering,Brazil, 2011, no. October.

[7] I. R. Muhamad, Y. A. Wahab, and S. Saat, "Identification of Water / Solid Flow Regime Using Ultrasonic Tomography," in IEEE International Conference on System Engineering and Technology (ICSET 2012), 2012, pp. 3-7.

[8] B. M. Wrobel, "Ultrasonic Measurement and Characterization of Liquid-Particle Flow," 2012.

[9] G. Gao, R. Dang, A. Nouri, H. Jia, L. Li, X. Feng, and B. Dang, "Sand rate model and data processing method for non-intrusive ultrasonic sand monitoring in flow pipeline," J. Pet. Sci. Eng., vol. 134, pp. 30-39, 2015.

[10] R. Abdul Rahim, N. W. Nyap, M. H. Fazalul Rahiman, and C. K. San, "Determination of Water and Oil Flow Composition Using Ultrasonic Tomography," J. Teknol., vol. 9, no. 1, pp. 19-23, 2007.

[11] M. H. Fazalul Rahiman, Z. Zakaria, R. Abdul Rahim, and W. N. Ng, "Ultrasonic tomography imaging simulation of two-phase homogeneous flow," Sens. Rev., vol. 29, no. 3, pp. 266-276, 2009.

[12] G. Steiner and C. Deinhammer, "Ultrasonic time-of-flight techniques for monitoring multi-component processes," Elektrotechnik und Informationstechnik, vol. 126, no. 5, pp. 200-205, May 2009.

[13] M. D. Supardan, Y. Masuda, A. Maezawa, and S. Uchida, "The investigation of gas holdup distribution in a twophase bubble column using ultrasonic computed tomography," Chem. Eng. J., vol. 130, no. 2-3, pp. 125-133, 2007.

[14] Y. Murai, Y. Tasaka, Y. Nambu, Y. Takeda, and S. R. Gonzalez A., "Ultrasonic detection of moving interfaces in gas-liquid two-phase flow," Flow Meas. Instrum., vol. 21, no. 3, pp. 356-366, 2010.

[15] Z. Zakaria, M. H. Fazalul Rahiman, and R. Abdul Rahim, "Simulation of the Two-Phase Liquid - Gas Flow through Ultrasonic Transceivers Application in Ultrasonic Tomography,” Sensors \& Transducer, vol. 112, no. 1, pp. 24-38, 2010.

[16] J. Abbaszadeh, H. A. Rahim, R. A. Rahim, S. Sarafi, M. N. Ayob, and M. Faramarzi, "Design procedure of ultrasonic tomography system with steel pipe conveyor," Sensors actuators A, vol. 203, pp. 215-224, 2013.

[17] J. Abbaszadeh, H. Binti, A. Rahim, R. Bin, A. Rahim, and S. Sarafi, "Frequency analysis of ultrasonic wave propagation on metal pipe in ultrasonic tomography system," 2014.

[18] M. Alssayh, A. Addali, D. Mba, and M. E. El-Alej, "Slug velocity measurement using acoustic emission technology," Proc. Inst. Mech. Eng. Part E J. Process Mech. Eng., vol. 230, no. 1, pp. 76-83, 2014.

[19] M. H. Fazalul Rahiman, Z. Zakaria, and R. Abdul Rahim, "Ultrasonic process tomographic imaging sensor: An approach utilising transceivers method,” 2008 Int. Conf. Comput. Commun. Eng., pp. 1147-1150, May 2008.

[20] M. H. Fazalul Rahiman, R. Abdul Rahim, H. Abdul Rahim, and N. M. Nor Ayob, "Novel Adjacent Criterion Method for Improving Ultrasonic Imaging Spatial Resolution,” IEEE Sens. J., vol. 12, no. 6, pp. 1746-1747, Jun. 2012.

[21] M. H. F. Rahiman, R. A. Rahim, H. A. Rahim, N. M. N. Ayob, E. J. Mohamad, and Z. Zakaria, "Modelling 
ultrasonic sensor for gas bubble profiles characterization of chemical column," Sensors Actuators B Chem., vol. 184, pp. 100-105, Jul. 2013.

[22] M. H. F. Rahiman, R. A. Rahim, H. A. Rahim, E. J. Mohamad, Z. Zakaria, and S. Z. M. Muji, "An investigation on chemical bubble column using ultrasonic tomography for imaging of gas profiles," Sensors Actuators B Chem., vol. 202, pp. 46-52, Oct. 2014.

[23] N. M. Nor Ayob, S. Yaacob, Z. Zakaria, M. H. Fazalul Rahiman, R. Abdul Rahim, and M. R. Manan, "Improving gas component detection of an ultrasonic tomography system for monitoring liquid/gas flow," in 2010 6th International Colloquium on Signal Processing \& its Applications, 2010, vol. 1, no. 1, pp. 1-5.

[24] N. M. Nor Ayob, M. J. Pusppanathan, R. Abdul Rahim, M. H. Fazalul Rahiman, F. R. Mohd Yunus, S. Buyamin, I. M. Abd Rahim, and Y. Md. Yunos, "Design Consideration for Front-End System in Ultrasonic Tomography," $J$. Teknol., vol. 64, no. 5, pp. 53-58, 2013.

[25] N. M. Nor Ayob, M. H. Fazalul Rahiman, Z. Zakaria, S. Yaacob, R. Abdul Rahim, and M. R. Manan, "Simulative study in liquid/Gas Two-Phase Flow Measurement for Dual-Plane Ultrasonic Transmission-Mode Tomography," $J$. Teknol., vol. 54, pp. 79-94, 2011.

[26] H. Zumbahle, Multiple Feedback Bandpass Filter Design. Analog Devices, 2008.

\section{BIOGRAPHIES OF AUTHORS}
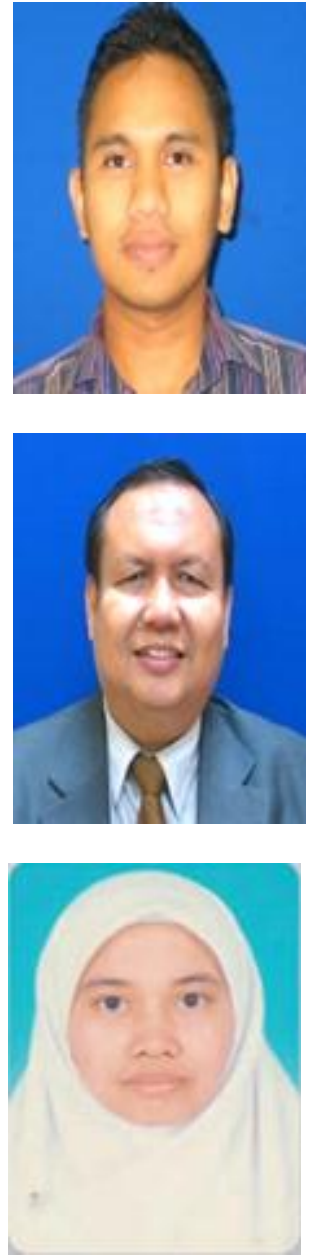

Mohd Fadzli Abd Shaib received his first degree in B.Eng. Electrical \& Electronics Engineering from Universiti Tenaga Nasional (UNITEN), Master in Electrical Engineering in Universiti Teknologi Malaysia (UTM) and currently pursuing his studies in the same university. He is an academic in Universiti Tun Hussein Onn Malaysia (UTHM) in Mechatronic and Robotics Department. His current research interests are process tomography and industrial automation.

Ruzairi Abdul Rahim received a B. Eng. degree with Honours in Electronic System and Control Engineering in 1992 from Sheffield City Polytechnic, UK. He received his Ph.D. in Instrumentation \& Electronics Engineering from Sheffield Hallam University, UK in 1996. At present he is a Professor and a Deputy Vice-Chancellor (Research), Universiti Tun Hussein Onn Malaysia. His current research interests are Process Tomography and Sensor Technology.

S.Z.M. Muji received her M.Sc. degree in Electric and Electronic Engineering from Universiti Sains Malaysia in 2004 and his $\mathrm{PhD}$ degree in Electronic Instrumentation at Universiti Teknologi Malaysia in 2012. She is currently a Associate Professor at the Faculty of Electrical and Electronic Engineering at Universiti Tun Hussein Onn Malaysia, focusing on Optical Tomography and application. 